\title{
Atmospheric Emitted Radiance Interferometer Handbook
}

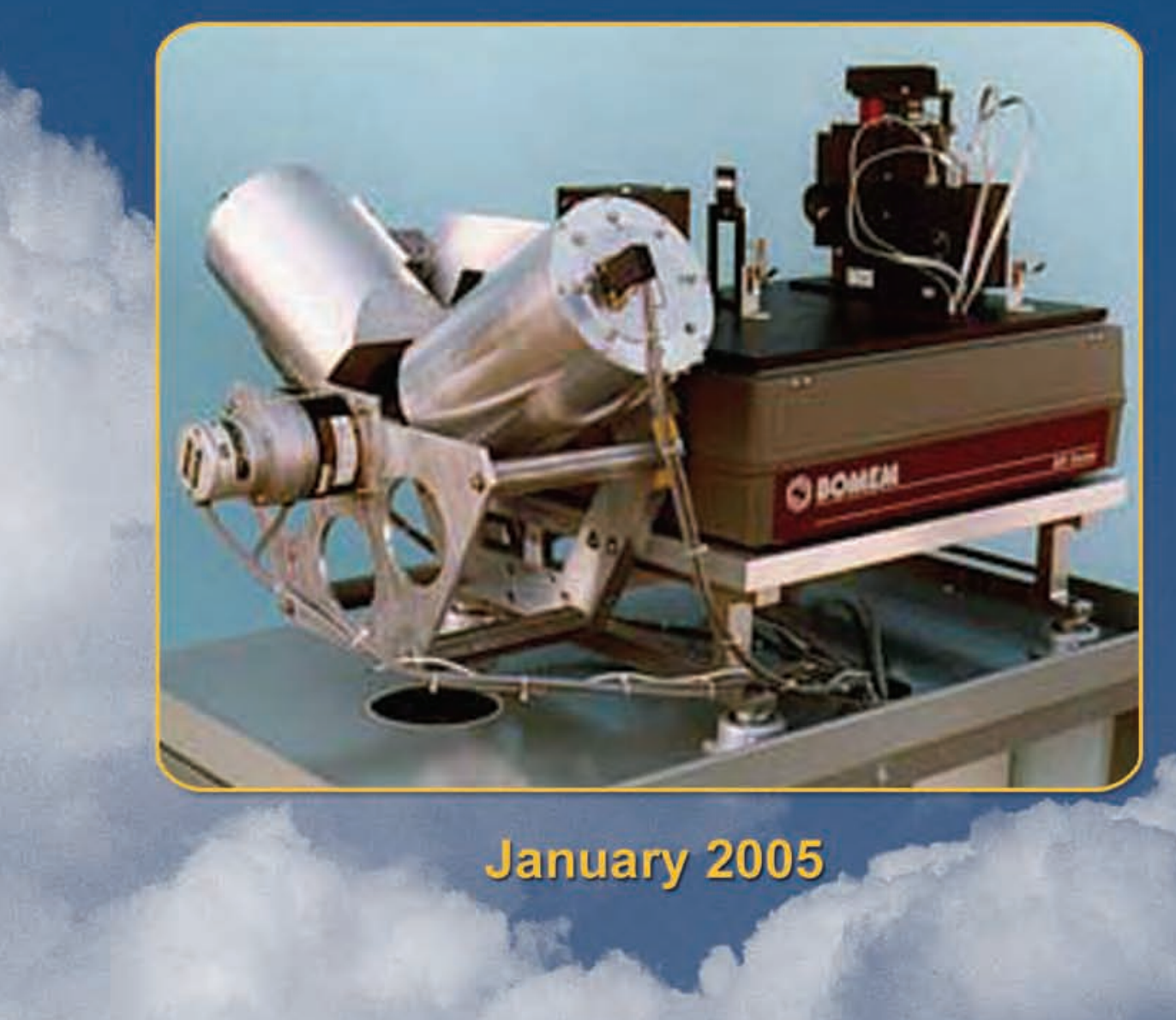


ARM TR-054

\section{Atmospheric Emitted Radiance Interferometer (AERI) Handbook}

January 2005

J. Demirgian

R. Dedecker

Work supported by the U.S. Department of Energy, Office of Science, Office of Biological and Environmental Research 


\section{Contents}

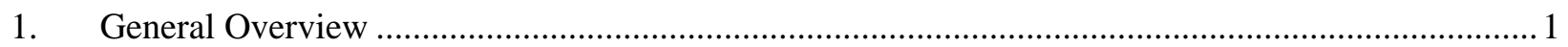

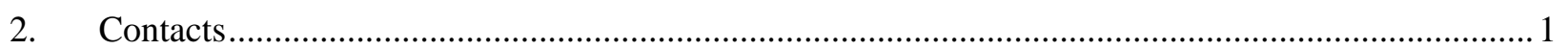

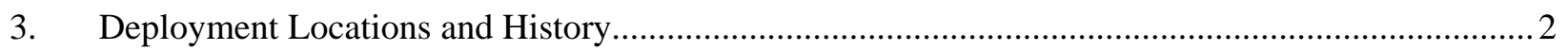

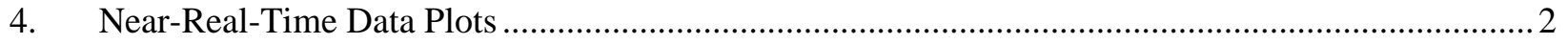

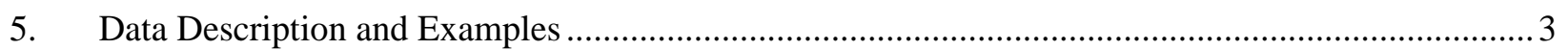

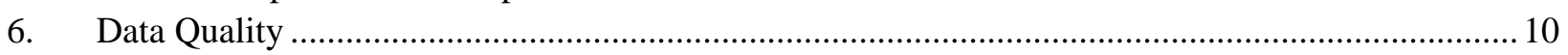

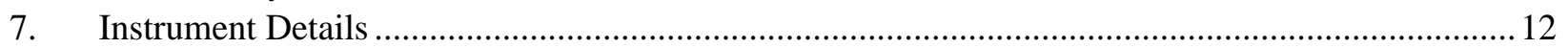




\section{General Overview}

The atmospheric emitted radiance interferometer (AERI) measures the absolute infrared (IR) spectral radiance (watts per square meter per steradian per wavenumber) of the sky directly above the instrument. The spectral measurement range of the instrument is 3300 to 520 wavenumbers $\left(\mathrm{cm}^{-1}\right)$ or 3-19.2 microns for the normal-range instruments and 3300 to $400 \mathrm{~cm}^{-1}$ or 3-25 microns, for the extended-range polar instruments. Spectral resolution is $1.0 \mathrm{~cm}^{-1}$. Instrument field-of-view is 1.3 degrees. A calibrated sky radiance spectrum is produced every 8 minutes in normal mode and every minute in rapid sampling mode. The actual sample scan time is $20-30 \mathrm{sec}$ in rapid sampling mode with periodic gaps when the instrument is looking at the blackbodies. Rapid sampling will become available in all AERIs. Rapid sampling time will eventually be reduced to data every 20 seconds. The AERI data can be used for 1) evaluating line-by-line radiative transport codes, 2) detecting/quantifying cloud effects on ground-based measurements of infrared spectral radiance (and hence is valuable for cloud property retrievals), and 3) calculating vertical atmospheric profiles of temperature and water vapor and the detection of trace gases.

\section{Contacts}

\subsection{Mentor}

Jack Demirgian

Argonne National Laboratory

9700 South Cass Avenue, Building 203

Argonne, IL 60439

Phone: 630-252-6807

E-mail: ftirman@anl.gov

\subsection{Instrument Developer}

Cooperative Institute for Meteorological Satellite Studies - SSEC

University of Wisconsin-Madison

1225 W. Dayton St.

Madison, WI 53706

Ralph Dedecker

Phone: 608-263-6779

E-mail: ralph.dedecker@ssec.wisc.edu

Fred Best

Phone: 608-263-6777

E-mail: fbest@ssec.wisc.edu

Denny Hackel

Phone: 608-263-0226

E-mail: dennyh@ssec.wisc.edu 


\section{Deployment Locations and History}

\begin{tabular}{|c|c|c|c|c|c|}
\hline $\begin{array}{c}\text { Serial } \\
\text { Number }\end{array}$ & $\begin{array}{c}\text { Property } \\
\text { Number }\end{array}$ & Location & $\begin{array}{c}\text { Date } \\
\text { Installed }\end{array}$ & $\begin{array}{c}\text { Date } \\
\text { Removed }\end{array}$ & Status \\
\hline SZM25321 & ? & SGP/C1 & $1995 / 04$ & current & Under repair \\
\hline SZM24017 & & SGP/C1 & $1993 / 10$ & $1995 / 01$ & Removed from service \\
\hline SZM433MT & & SGP/E14 & $2003 / 12$ & current & operational \\
\hline SZM433MT & & Hillsboro & $1998 / 12$ & $2003 / 12 / 11$ & relocated E14 \\
\hline SZM433J6 & & Vici & $2002 / 04$ & $2003 / 06 / 09$ & To Darwin \\
\hline SZM433J5 & & Vici & $1998 / 11$ & $2002 / 04$ & AERI-Bago \\
\hline SZM433G5 & & Morris & $1998 / 12$ & $2003 / 11 / 05$ & UW \\
\hline SZM433G6 & & Purcell & $1998 / 11$ & $2003 / 11 / 05$ & UW \\
\hline SZM433JA & & NSA/C1 & $2002 / 07$ & current & operational \\
\hline SZM433EP & & NSA/C1 & $2002 / 04$ & $2002 / 07$ & NSA-2 \\
\hline SZM433JA & & NSA/C1 & $2001 / 01$ & $2002 / 04$ & NSA-1 \\
\hline SZM433EP & & NSA/C1 & $1998 / 02$ & $2001 / 01$ & NSA-2 \\
\hline SZM433JA & & SHEBA & $1997 / 10$ & $1999 / 01$ & NSA-1 \\
\hline SZM433G1 & & TWP-Nauru & $2002 / 03$ & $2005 / 03$ & being repaired \\
\hline SZM433J6 & & TWP-Nauru & $2000 / 07$ & $2002 / 03$ & Darwin \\
\hline SZM433G1 & & TWP-Nauru & 1998 & $2000 / 07$ & Nauru \\
\hline SZM433J6 & & Darwin & $2004 / 12$ & current & operational \\
\hline SZM433EP & & NSA-2 & $2003 / 12$ & $2004 / 08$ & UW \\
\hline SZM433EP & & Oliktok Pt. & $2004 / 09$ & $2004 / 10$ & UW \\
\hline
\end{tabular}

The Surface Heat Budget of the Arctic Ocean (SHEBA) and Southern Great Plains (SGP) Boundary Facility sites (Hillsboro, Morris, Purcell, Vici) have been discontinued. SHEBA was an experiment that took place on the arctic ice from 1997-1999. The boundary facilities circled the SGP Central Facility (CF) and provided a complete data set for conditions at the SGP. The data collected during the operation of these facilities are available from the Atmospheric Radiation Measurement (ARM) Program's archive (http://www.archive.arm.gov/).

\section{Near-Real-Time Data Plots}

Real time plots are available on the Internet at http://bora2.ssec.wisc.edu:8050.

A typical web page is shown below with the Darwin site selected. 


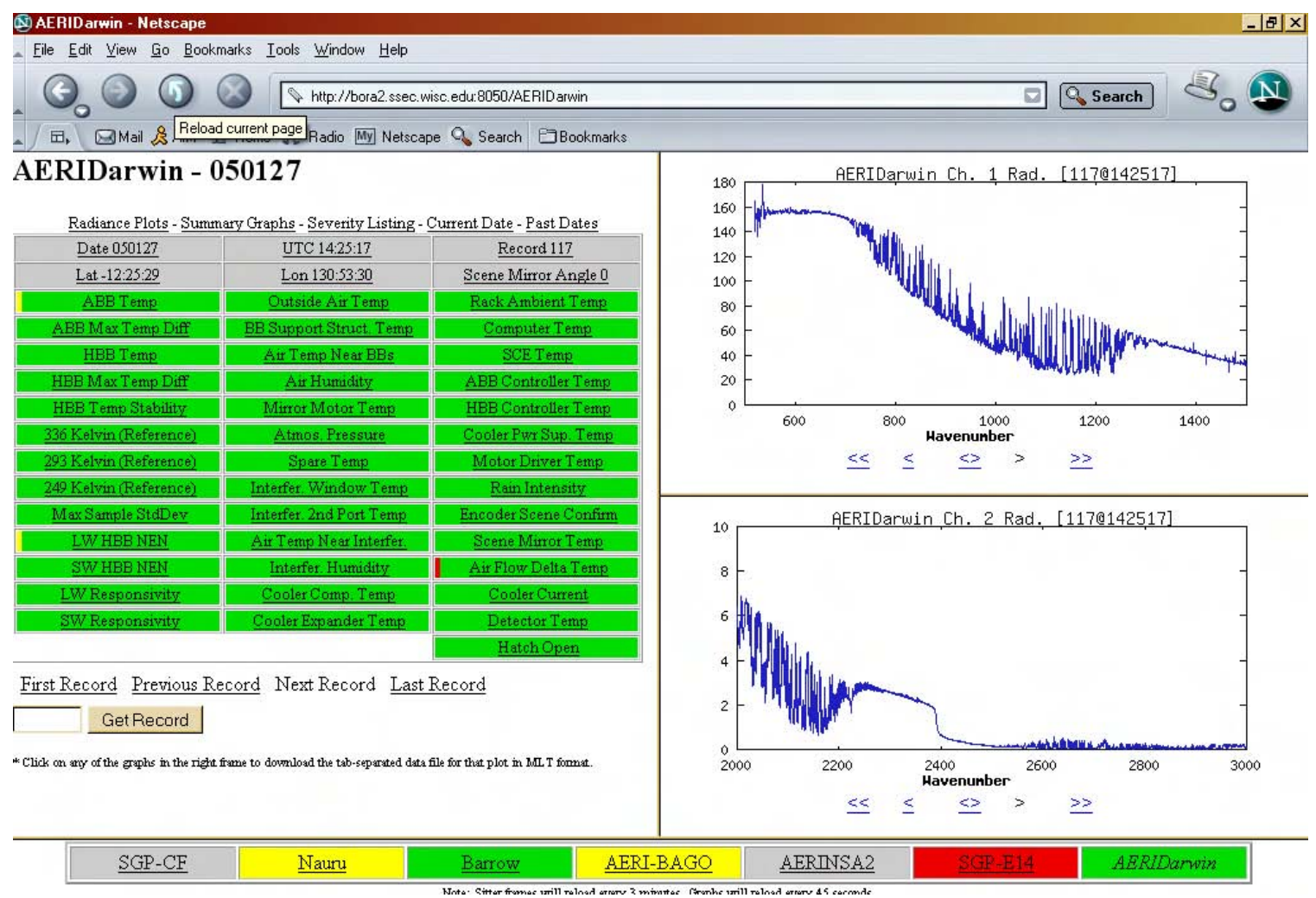

The user can click on the buttons on the bottom of the page to select the location. The Tropical Western Pacific (TWP) sites are Nauru and Darwin. The SGP sites are SGP CF and SGP-E14. The two instruments are collocated at the CF for data comparison purposes. The North Slope of Alaska (NSA) site is Barrow. Currently, the Barrow AERI is the only one in rapid-sampling mode. A second instrument (NSA2) will be installed on the NSA site; it will be labeled NSA2. The AERI_BAGO is a mobile instrument operated by the University of Wisconsin.

The two spectra on the right of the web page represent the short (bottom) and long (top) wave infrared plots. A summary of data flags are located on the left. The user can click on any of the summary buttons for further information on each item. The summary plots are available by selecting the choice above summary of the data flags.

\section{Data Description and Examples}

\subsection{Data File Contents}

The AERI data files are stored in both raw and calibrated files. The nomenclature is as follows:

\section{Raw data files}

yymmddF1.CXS yymmddF2.CXS yymmddB1.CXS yymmddB2.CXS yymmddF1.UVS

Complex uncalibrated spectra for Channel 1, Fwd. direction Complex uncalibrated spectra for Channel 2, Fwd. direction Complex uncalibrated spectra for Channel 1, Back. direction Complex uncalibrated spectra for Channel 2, Back. direction Uncalibrated variance spectra for Channel 1, Fwd. direction 
yymmddF2.UVS yymmddB1.UVS yymmddB2.UVS

\section{Calibrated data files} yymmddC1.RNC yymmddC2.RNC yymmddF1.CSV yymmddF2.CSV

\section{Control files} yymmdd.PAR yymmdd.QC yymmddhh.SIT SUMARY.SCR RADIANCE.SCR AESITTER.SCR
Uncalibrated variance spectra for Channel 2, Fwd. direction Uncalibrated variance spectra for Channel 1, Back. direction Uncalibrated variance spectra for Channel 2, Back. direction

Real normalized calibrated spectra for Channel 1

Real normalized calibrated spectra for Channel 2

Calibrated sky variance spectra for Channel 1, Fwd. direction

Calibrated sky variance spectra for Channel 2, Fwd. direction

Configuration parameters used for calibration

ASCII file listing data deviation from normal range hh is UTC hour - condensed abnormal conditions report

ASCII file containing controls for graphic product displays of summary products ASCII file containing controls for graphic product displays of radiance spectra ASCII file containing "Normal" data ranges of summary product items and graphic display products

ARM converts the .RNC, .CSV, and .SUM files into netCDF format.

\subsubsection{Primary Variables and Expected Uncertainty}

1. Absolute spectral radiance of the sky in units of watts per square meter per steradian per wavenumber.

2. Sky brightness temperature as a function of wavenumber in units of degrees Kelvin.

In addition, calculated quantities are also available:

1. Variance of sky infrared spectral radiance as a function of wavenumber.

The value-added procedure (VAP), consisting of the vertical atmospheric profiles of temperature, potential temperature, mixing ratio, and relative humidity, is also available (AERIPROF).

\subsubsection{Definition of Uncertainty}

The uncertainty in the primary and secondary quantities measured are discussed in detail in a review by R.O. Knuteson et al. (see Reference 2).

Copies of this paper are available by email from Robert.knuteson@ssec.wisc.edu or from the instrument mentor at ftirman@anl.gov.

\subsubsection{Secondary/Underlying Variables}

See above 


\subsubsection{Diagnostic Variables}

The following variables reside in the .SUM files. They are critical variables. If they are flagged red, data quality will usually be compromised.

- Encoder Scene Confirm - Tells us if the mirror is operational or in a "safe" position. If this flag is red it's usually a show stopper. However, sometimes the set point changes after work is done on the instrument. This happened at Barrow in December 2003.

- Hatch Open - If this flags, the hatch is either closed or in an intermediate position. There is no sky data when the hatch is closed. There is still calibration data.

- $\quad$ Detector Temp - A warm detector means degraded data.

- $\quad$ LW HBB NEN - Noise-equivalent Radiance in Hot Blackbody at $1000 \mathrm{~cm}-1$ ) measures detector noise in the long wave. High values indicate degraded data.

- $\quad$ SW HBB NEN - Noise-equivalent Radiance in Hot Blackbody at $2500 \mathrm{~cm}-1$ ) measures detector noise in the shortwave. High values indicate degraded data.

- $\quad$ LW Responsivity - Characteristic value representing overall longwave channel responsivity). Measures the sensitivity of the detector. Low values indicate a problem; very low values affect data quality.

- $\quad$ SW Responsivity - Characteristic value representing overall shortwave channel responsivity. Measures the sensitivity of the detector. Low values indicate a problem; very low values affect data quality.

- $\quad$ Rain Intensity - if there is rain there should be no data. The rain sensor, when dirty, will flag under sunny skies. The sensor has an analog output. The rain sensor is located inside the hatch near the sky aperture and is used to flag the critical condition of rain falling on the AERI sky aperture. If rain is detected, the AERI scene mirror will be safe to the down-looking position. This rain sensor is not used to close the AERI viewing hatch; it could be viewed as an independent indicator of a situation where the hatch has not closed to protect the AERI interferometer front end in the presence of rain.

\subsubsection{Data Quality Flags}

The following flags indicate that there was a problem in calibration because of a temperature or electronic instability of the ambient and hot blackbodies. Slight deviations from optimum values will not affect data quality. Larger deviations will cause more noise and can affect data quality for some uses but not for others. The significance of these deviations is noted by the mentor in Section 6.2, "Data Reviews by the Instrument Mentor.” 
The difference in temperature between the ambient and hot blackbody temperatures provide the temperature calibration for the sky data. Larger differences between the ambient and hot blackbodies improve the calibration. Sky temperatures must lie within the ambient and hot blackbody temperatures.

- $\quad$ ABB Temp (calibrationCBBtemp) Ambient blackbody temperature

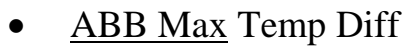

- HBB Temp (calibrationHBBtemp) Hot blackbody temperature

- $\quad$ HBB Max Temp Diff

- $\quad$ HBB Temp Stability

- 336 Kelvin (Reference) (fixed2500ohmResistor)

- 293 Kelvin (Reference) (fixed12KohmResistor)

- 249 Kelvin (Reference) (fixed97KohmResistor)

- Max Sample StdDev.

\section{Diagnostic and maintenance}

These flags help us determine what may be causing a problem. Most are temperature and humidity problems. Some flags (noted) tell us a critical component is failing. This gives us warning to replace it before it fails. Some indicate when routine maintenance is required. I have included a description under the more important flags.

- $\quad$ Cooler Current - This flags when a cooler (or detector dewar) is beginning to fail. Immediate action is warranted. It can also lead to a warming of the detector, which will affect data quality.

- Cooler Expander Temp - If the expander gets too warm, the cooler cannot cool properly. The problem is caused by dirty cooling fins (or the cooling motor failed).

- Outside Air Temp - If the outside air is too warm, the ambient blackbody is too warm and the difference between the ambient and hot blackbodies is too small. This increases noise and affects data quality. We cannot correct ambient temperature. This is never a problem at Barrow.

- Scene Mirror Temp - enclosure is too warm; usually flags with outside air.

- $\quad$ Air Flow Delta Temp - difference between frontEndFanAirHeatedTemp and frontEndFanAirUnheatedTemp; indicative of front-end air flow. Flags when outside air is too warm or filter is plugged.

The following flags indicate the instrument enclosure is too warm, which can affect how the instrument functions and cause components to fail.

- $\quad$ BB Support Struct. Temp

- Air Temp Near BBs

- Spare (Shelter) Temp

- Interfer. Window Temp

- Interfer. 2nd Port Temp

- Air Temp Near Interfer.

- Rack Ambient Temp

- Computer Temp. 
The following indicate a component is overheating, probably leading to a failure:

- Cooler Comp. Temp

- Mirror Motor Temp

- SCE Temp (Signal conditioning electronics inside air temperature)

- ABB Controller Temp

- HBB Controller Temp

- Cooler Pwr Sup. Temp

- Motor Driver Temp.

Atmospheric conditions we can do nothing about but may clue us into a problem:

- Air Humidity (atmosphericRelativeHumidity)

- Atmos. Pressure.

Warning to replace desiccant and avoid serious internal damage:

- Interfer. Humidity

- Optics Humidity.

\subsubsection{Dimension Variables}

All AERI data files contain Universal Time Coordinates (UTC) time, date, longitude, latitude, and file number.

\subsection{Annotated Examples}

A complete set of detailed updated examples is available at: http://cimss.ssec.wisc.edu/aeri. Some of the more commonly used ones are noted below.

The following examples are explained in more detail at: http://cimss.ssec.wisc.edu/aeri/science/.

\section{Atmospheric Profiling}

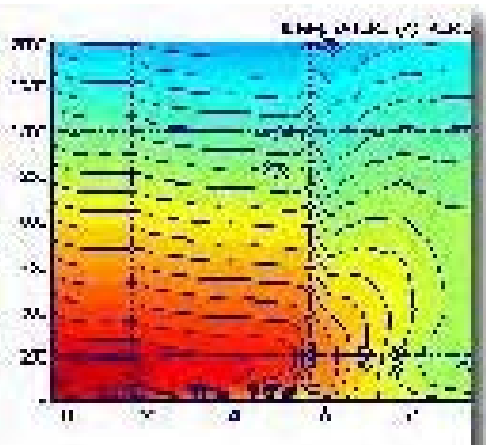

The AERI instrument detects vertical and temporal (time) changes of temperature and water vapor in the lower part of the earth's atmosphere via changes in measured down-going IR radiation coming from the lower atmosphere. With a temporal resolution of less than 10 minutes and an optimal vertical resolution of 100 meters, the AERI instrument can observe meteorologically important mesoscale phenomena, such as boundary-layer evolution, cold/warm frontal passages, dry lines, and thunderstorm outflow boundaries. These temperature and moisture vertical retrievals provide data for stability index monitoring, planetary boundary-layer (PBL) research, mesoscale model initialization, verification, and nowcasting. 


\section{Cloud Retrieval}

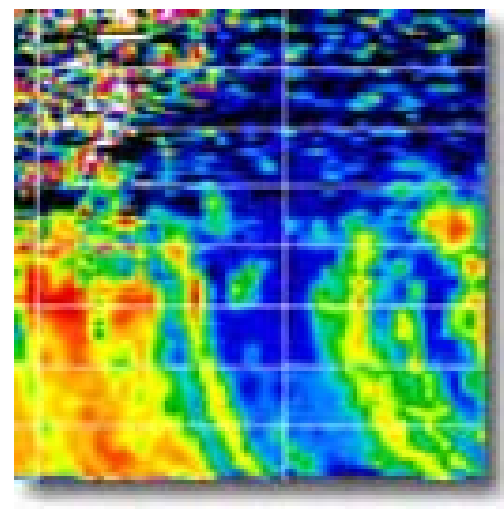

Ground-based AERI and Raman light detection and ranging (lidar) measurements are used to infer cirrus cloud absorption optical depth and effective particle size. The high spectral resolution AERI measurements allow inversion of the infrared radiative transfer equation between gaseous absorption lines (e.g., regions of minimal atmospheric emission), referred to as microwindows, to derive the cloud infrared absorption optical depth. lidar data are used to determine cloud boundaries, while also providing an independent measurement of cloud optical depth. Optical depth spectral variation, across the 8-to-12micron atmospheric window, yields information on particle size and shape. A best fit of absorption optical depth to the measured absorption optical depth is used to determine the effective radius of particles within the cloud.

\section{AERI Temperature and Water Vapor Research}

MARITIME PACIFIC BAND 1 RADIANCE SPECTRA

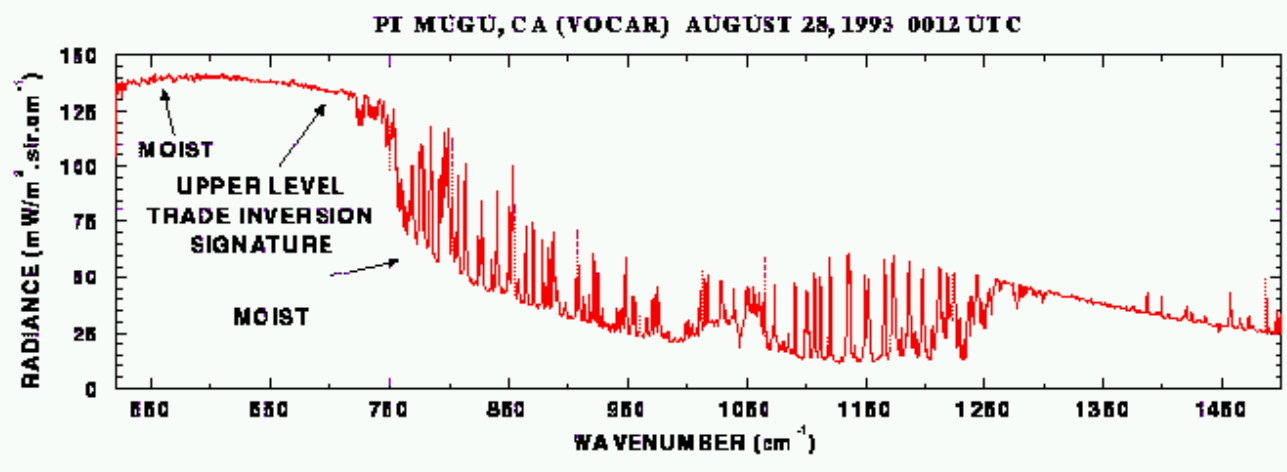

CONTINENTAL POLAR BAND 1 RADIANCE SPECTRA

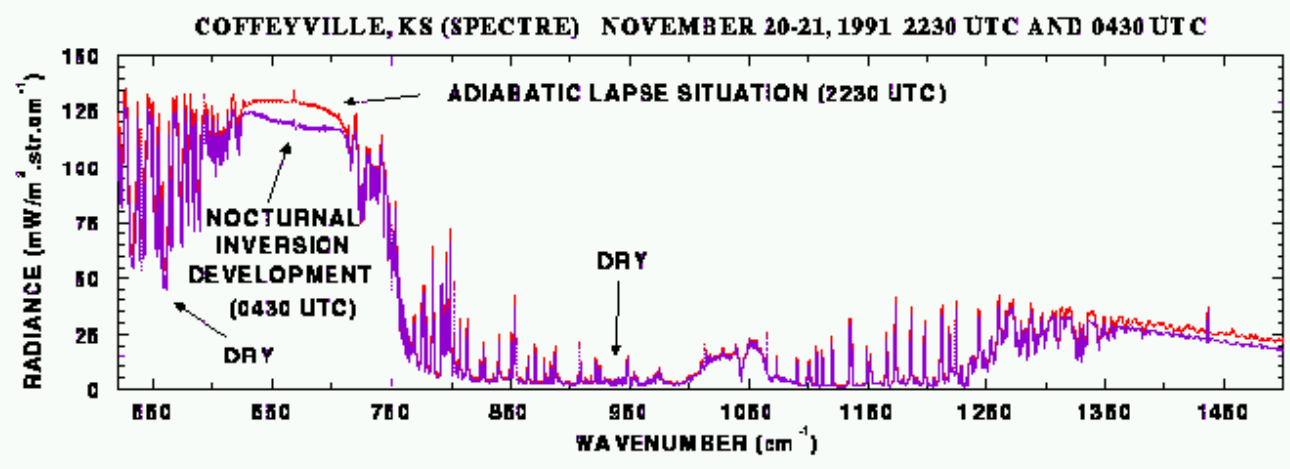

The AERI is used to produce temperature and water vapor profiles every ten minutes in the PBL, the lowest $3 \mathrm{~km}$ of the earth's atmosphere. AERI measures IR radiation (3 to $18 \mathrm{um}$ ) passively, yielding high-resolution radiance spectra (less than $1 \mathrm{~cm}^{-1}$ ). The spectra are transformed to vertical temperature and water vapor profiles by inverting the IR radiative transfer equation (RTE). Several field experiments have confirmed AERI's high-temperature and water-vapor retrieval skill in the PBL. 


\subsection{User Notes and Known Problems}

The data flags listed in section 5.1.3 determine data quality. They are noted as green, yellow, or red in the .SUM file. The green, yellow, red limits are available on the web page listed in Section 4 of this web page, http://bora2.ssec.wisc.edu:8050 . When accessing data using netCDF format, the color of the data are not noted. The user should obtain the limits and ensure the quality of the data that are used. Data marked as red will have much larger error limits.

Individual occurrences of "red" data are not recorded in a data quality report (DQR) because of the large number of occurrences of rain or snow that would cause the hatch to close and put the mirror in a safe position. The instrument remains running but produces a flat line spectrum. The user must determine when rain or snow events occur using these data flags. There are too many occurrences to file DQRs for each snow, rain, or shower event.

\subsection{Frequently Asked Questions}

\section{Are data taken continuously?}

Spectra are coadded and processed every 8 minutes for standard sampling AERIs. In rapid sampling mode (spectra every minute), less spectra are coadded. Eventually, all AERIs will be in rapid sampling mode. Because less spectra are coadded in rapid sampling mode, the data have a higher random noise component. A VAP is being developed that reduces/removes the uncorrelated component of the random noise.

\section{Are data taken at night or on cloudy days?}

Data are taken as long as the precipitation sensors on the instrument hatch are not triggered. This guards the steering mirror from water and snow that would obscure the optical throughput.

\section{Are independently acquired data on temperature and water vapor profiles available for comparison? If so, from what source?}

Radiosonde data (from weather balloon launches) are available in 3-hour time intervals. Other remote sensors provide profiles of water vapor and temperature (radio acoustic sounding system (RASS), Raman lidar, MWRP).

\section{Are there any other references you can recommend?}

See the reference section at the bottom of this web page.

Please submit questions to the instrument mentor, Dr. Jack Demirgian, ftirman@anl.gov. 


\section{Data Quality}

\subsection{Data Quality Health and Status}

Data quality for each spectrometer can be obtained from the following web page. http://cygnus.mrcsb.com/dqhands/cgi-bin/dqmenu.pl.

A typical page is shown below.

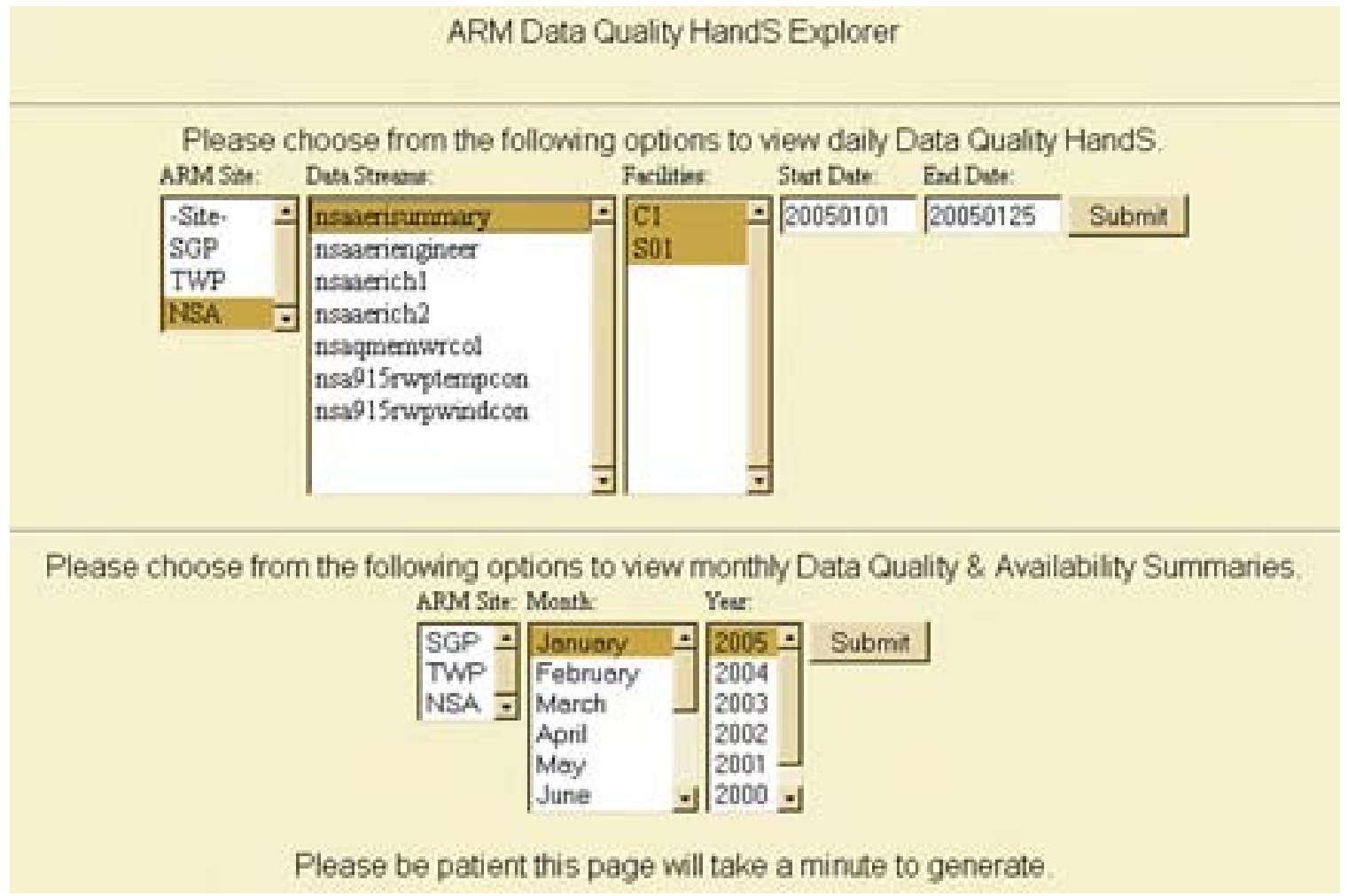

The following links go to current data quality health and status results:

- $\quad$ DQ HandS (http://dq.arm.gov/) for Data Quality Health And Status

- NCVweb (http://dq.arm.gov/ncvweb/ncvweb.cgi) for interactive data plotting.

The tables and graphs shown contain the techniques used by ARM's data quality analysts, instrument mentors, and site scientists to monitor and diagnose data quality.

ARM netCDF file header descriptions may be found at AERI

(http://science.arm.gov/tool/dod/showdod.php?Inst=aeri) Data Object Design Changes.

\subsection{Data Reviews by Instrument Mentor}

Mentor reviews include an overview of all the instruments and MS Excel spreadsheets covering the values for data flags that flagged yellow or red. 
Previous mentor reviews beginning from 2000 and all spreadsheets are available from the mentor. Contact Jack Demirgian, ftirman@anl.gov .

\subsection{Data Assessments by Site Scientist/Data Quality Office}

This section is not applicable to this instrument.

\subsection{Value-Added Procedures and Quality Measurement Experiments}

Many of the scientific needs of the ARM Program are met through the analysis and processing of existing data products into VAPs. Despite extensive instrumentation deployed at the ARM sites, there will always be quantities of interest that are either impractical or impossible to measure directly or routinely. Physical models using ARM instrument data as inputs are implemented as VAPs and can help fill some of the unmet measurement needs of the program. Conversely, ARM produces some VAPs not to fill unmet measurement needs, but to improve the quality of existing measurements. In addition, when more than one measurement is available, ARM also produces "best estimate" VAPs. A special class of VAP, called a Quality Measurement Experiment (QME), does not output geophysical parameters of scientific interest. Rather, a QME adds value to the input datastreams by providing for continuous assessment of the quality of the input data based on internal consistency checks, comparisons between independent similar measurements, or comparisons between measurement with modeled results, and so forth. For more information see:

- $\quad$ AERI PROF, (http://science.arm.gov/vaps/aeripro.stm) compares retrieved profiles from AERI with the profiles from radiosondes.

- Water vapor and temperature profiles are available at http://cimss.ssec.wisc.edu/aeri/.

The VAPs listed above are also the following QMEs:

- QME AERI PROF, (http://science.arm.gov/vaps/qmeapro.stm) compares retrieved profiles from AERI with the profiles from radiosondes.

- QME AERI/LBLRTM, (http://science.arm.gov/vaps/qmealbl.stm) for analysis of the QME AERI/LBLRTM residuals. Compares radiances retrieved by AERI with those calculated by the LBLRTM (line-by-line radiative transfer model), using sonde data for pressure- and temperaturebroadening calculations.

\subsubsection{Examples of Data}

The following plot shows two spectra taken with the AERI. Recalling that the spectra is emission spectra from the atmosphere, the absence of emission at 950 and the weak emission at 550 wavenumbers observed in the lower panel is evidence for a very dry air mass. In fact, the lower panel is a continental polar air mass (very dry). Compare these same spectral regions with the upper panel taken at Point Magu, California on the southern California coastline. 


\section{MARITIME PACIFIC BAND 1 RADIANCE SPECTRA}

PI MUGU, CA (YOCAR) AUGUST 28, 19930012 UT C

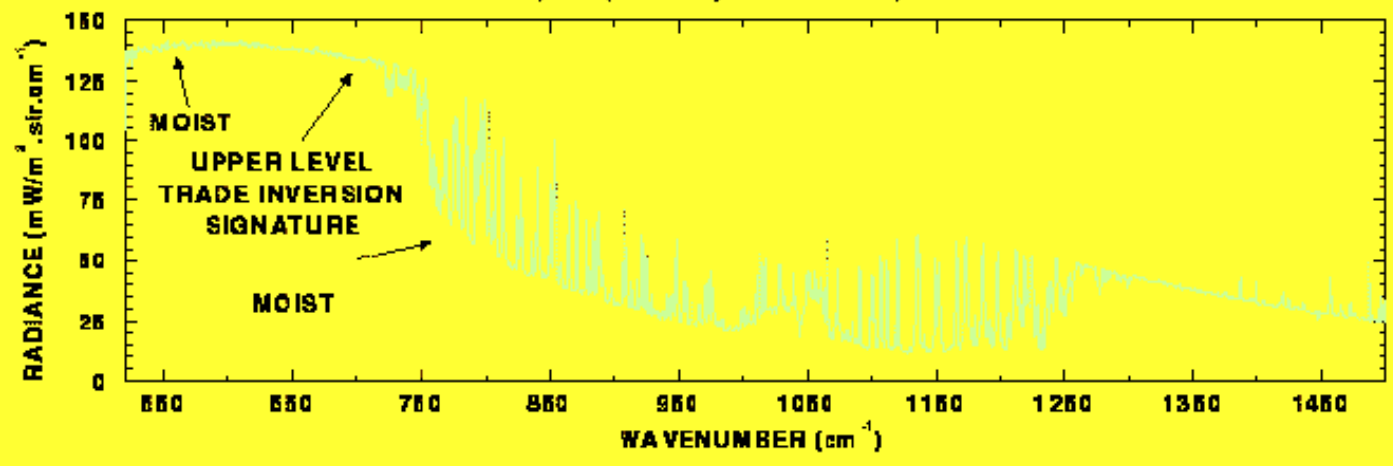

CONTINENTAL POLAR BAND 1 RADIANCE SPECTRA COFFEYVILLE, KS (SPECTRE) NOVEMBER 20-21, 19912230 UTC AND 0430 UT C

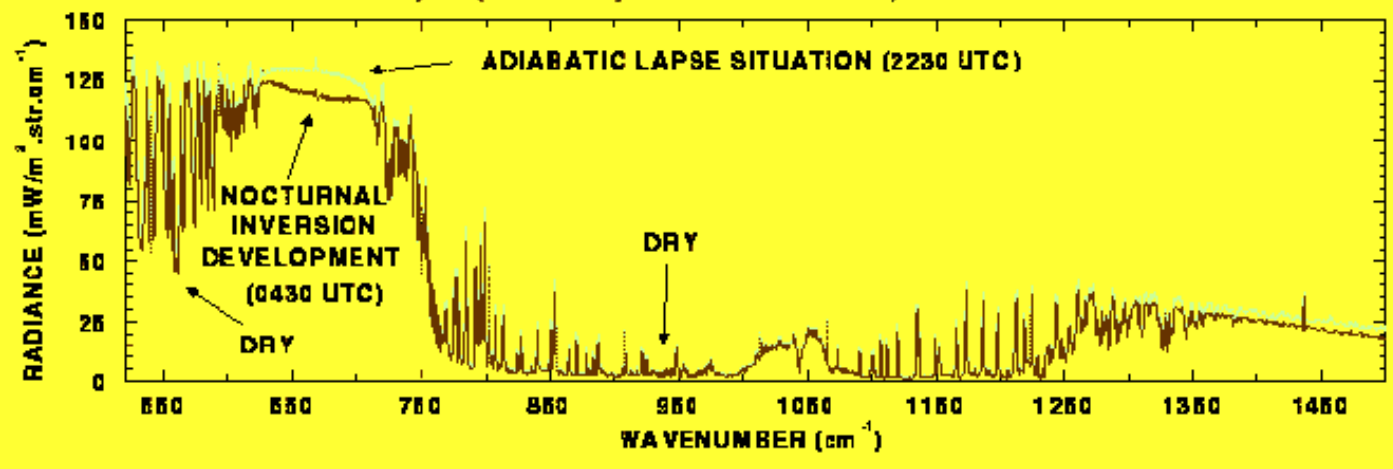

This link (http://www.joss.ucar.edu/cgi-bin/joss-

catalog/sheba/ship_instrument_browse?isindex=AERI_CHAN1 ) provides data from the deployment of the AERI-ER at the SHEBA ice station. Note the extended wavelength coverage in the low wavenumber end (long wavelengths). As you click on the "bear paws" next to each available date, note occurrences of dry air masses (weak emission at 950 and 550 wavenumbers: November 28, 1997). However, on some days there is a smooth spectral feature indicative of low clouds (e.g., November 11, 1997; actually snowed on this day).

More data examples appear below under VAPs and Data Quick-Looks.

\section{Instrument Details}

\subsection{Detailed Description}

\subsubsection{List of Components}

The AERI radiometer is composed of six subsystems, which include the following: 1) the interferometer, 2) the detector; 3) the scene-scanning optics; 4) the calibration blackbodies with temperature controller; 5) a PC-based instrument control, data acquisition, data processing computer with custom software running under OS/2, and 6) an automated viewport hatch, which serves to protect the AERI optics in inclement weather. 
1. Interferometer (shown below) - The "heart" of the AERI radiometer is a Fourier- transform IR (FTIR) spectrometer manufactured by Bomem Corp., Quebec, Canada. This spectrometer, dubbed the model MB-100, is a four-port Michelson interferometer employing a flex-pivot mirror translation mount and corner cube reflectors. This design is very robust against ambient vibrations and temperature fluctuations and is well-suited for a field-deployed instrument. In addition, the use of a flex-pivot mirror-scanning system eliminates the need for bearing surface maintenance associated with conventional interferometer designs.

2. Detector - The AERI IR detector is a two-layer "sandwich" design (InSb and HgCdTe) manufactured by Infrared Associates.

3. The scene-scanning optics.

4. Calibration blackbodies.

5. Instrument control Hardware.

6. Hatch.

\section{AERI-00 Interferometer Block}

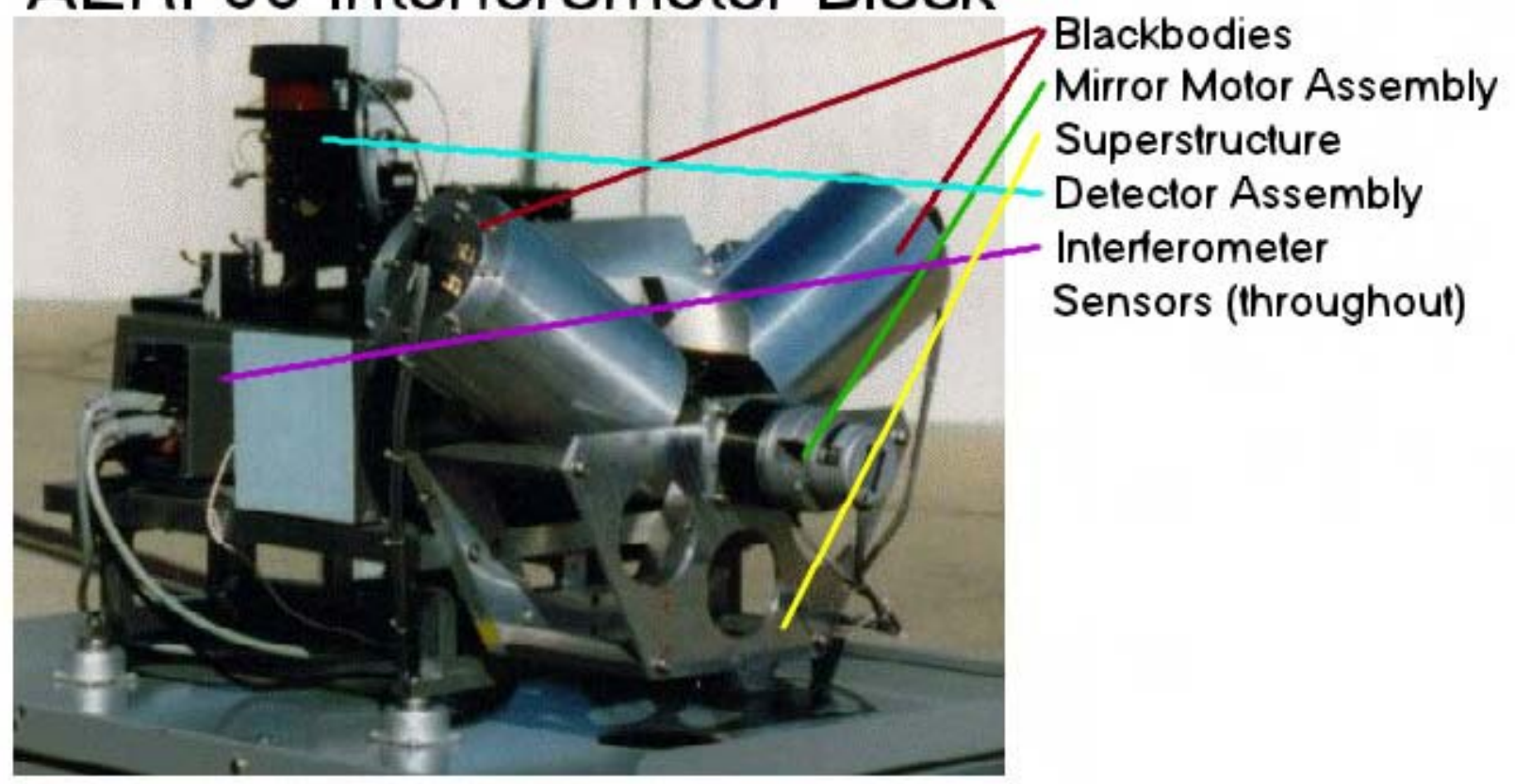




\subsubsection{System Configuration and Measurement Methods}

The AERIs are located in trailers at the SGP, NSA, and TWP sites. The viewing mirror and the two calibration blackbodies are separated by a thermal barrier from the other half of the AERI, which consists of a: Bomem Interferometer and the data acquisition computer. The viewing mirror is at ambient temperature. The Bomem and computer are at room temperature in the trailer. The viewing mirror is rotated to view the sky and alternately the calibration sources.

\subsubsection{Specifications}

Resolution of instrument is one wavenumber $(1 / \mathrm{cm})$. Range of wavelengths is 520 to 3300 wavenumbers or 400 to 3300 wavenumbers in the ER polar detector. Data are collected only in the atmospheric windows. Maximum range is top of atmosphere on a clear-sky day. Measurements are taken every 8 minutes in standard mode and every minute in rapid sampling mode. The instrument views straight up into the atmosphere with a 1.3-degree field-of-view.

\subsection{Theory of Operation}

The IR spectra is gathered by the AERI instrument and the operation of the interferometer follows. The FTIR spectrometers measure light absorbed or emitted from a sample as a function of wavelength. They consist of an optical system for collecting light and concentrating it, an interferometer for algebraically combining the light from the two light paths, a detector to change the light intensity into an electrical signal, signal conditioning electronics, and a computer for extracting spectral data from the signal using FTIR methods.

In general, interferometers combine light from two light paths algebraically resulting in variations in light intensity across the aperture of the interferometer called interference fringes (for non-coincident or nonidentical wavefronts). One light path is scanned to vary the optical path length. The other path is a reference path. Consider a Michelson interferometer looking at monochromatic light from a collimated expanded laser beam, in which the incident beam is split into two equal length paths by a beam-splitter. Also assume that each path ends in a plane front surface mirror, which is aligned such that the surfaces are normal to the beam.

If the mirrors are aligned exactly so that the distance traveled by light is point-for-point identical over the beam for the two paths, the observer will see a uniformly bright entrance aperture through the interferometer. If the paths differ by a half-wavelength, the observer will see a uniformly black aperture. For intermediate positions, the intensity will be proportional to the cosine of the phase angle (relative fraction of a half-wavelength path difference).

This observation is true only for monochromatic light. If a second monochromatic wavelength is added, the cross-section will have different intensity for each of the two wavelengths because the difference in path lengths between the two paths will be a different multiple (or fraction) of wavelengths for each wavelength. For additional wavelengths, intensity contributions are algebraically summed. 
If light entering the interferometer is an unknown combination of wavelengths, like light from a source having a broadband spectrum, the result will be a complex combination of intensities due to the multiple wavelengths. As the optical path length of one path is slowly but uniformly changed, the difference in path length for each wavelength will change. Because the wavelengths are different, the path difference expressed as a factor of the wavelength will be different for each wavelength, and will change at a different rate. Path differences, resulting in a variation in output intensity, will change more quickly for short wavelengths than for long wavelengths. If a detector converts the intensity variations into electrical variations, temporal signal will be a superposition of cosines with periods representing the time variations in intensity. Analysis of this series into its component frequency components (with coefficients characteristic of the relative intensities of the individual wavelength components present in the incident light) is accomplished using a FTIR algorithm. The algorithm is ideally suited to breaking down signals comprising a series of sines or cosines, resulting in the electromagnetic spectrum of the incident light.

The function of the Helium Neon laser in a modern FTIR is often misunderstood. Its sole purpose is to measure the position(x) of the moving mirror, the so-called retardation distance. The helium neon laser is used in a separate interferometer, called the reference interferometer, that shares the moving mirror with the IR interferometer. In this way, fringes are counted in the reference interferometer, which allows a precise measurement of the retardation position, $x$. With the interferrogram, I(x), from the IR interferometer, and the retardation position, $\mathrm{x}$, the spectra can be obtained by a fast fourier transform.

\subsection{Calibration}

\subsubsection{Theory}

Two blackbody sources, one at ambient temperature and the other at $330 \mathrm{~K}$ are used to calibrate the instrument. The two sources are used to determine the slope and offset, which define the linear instrument response at each wavenumber. (see reference 1) The AERI views these two blackbodies every two minutes. Magnitude of the difference between these blackbody spectra is then formed to compute the responsivity and offset for the instrument.

After application of the responsivity and offset, the brightness temperature vs. wavenumber agrees with the known temperatures (290K and 330K) within 1 Kelvin. The residual error is thought to originate from two sources: angular dependence in the beam-splitter coatings and emission from the beam-splitter coatings. Of these two sources, the largest error appears to originate from emission in the beam-splitter. (see reference 1).

\subsubsection{Procedures}

Calibration procedures are performed automatically by the software. Any anomalies are reported in the .SUM file and evaluated by the instrument mentor. See references 2 and 3 to see how calibration is automatically performed. 


\subsubsection{History}

Because this instrument takes a calibration run every 2 minutes, the best history is to obtain views of the blackbody brightness temperature curves (available only from the Multiple AERI Data System (MADS) software, instrument mentor). Inspections of these curves by the mentor in the past has revealed no anomalies in calibration.

\subsection{Operation and Maintenance}

\subsubsection{User Manual}

There is no User Manual.

\subsubsection{Routine and Corrective Maintenance Documentation}

This information is available from the instrument mentor or the Space Science and Engineering Center (SSEC) and is only to be performed by the site techs and mentors.

\subsubsection{Software Documentation}

The software for operating the instrument is called MADS. There is no manual. The interface is selfexplanatory.

\subsubsection{Additional Documentation}

The user may want to contact the instrument manufacturer, Bomem, for instrument details and SSEC for details on how the Bomem was converted to an AERI.

\subsection{Glossary}

FTIR - Fourier Transform Infrared

HgCdTe - Mercury Cadmium Telluride Detector for long wavelength infrared detection (5 to 15 microns).

InSB - or 'insbee' detector optimized for near-to-mid-infrared 1 to 5 microns.

Wavenumber - the inverse of the wavelength in centimeters. For example, one micron wavelength (.0001 $\mathrm{cm}, 1 \mathrm{e}-4)$ becomes 10,000 wavenumbers when inverted. Wavenumber is useful because the photon energy is equal to the wavenumber times planck's constant times two pi (i.e., the wavenumber is proportional to the photon energy).

\subsection{Acronyms}

AERI atmospheric emitted radiance interferometer

AERI-ER atmospheric emitted radiance interferometer-extended range 


$\begin{array}{ll}\text { ARM } & \text { Atmospheric Radiation Measurement (Program) } \\ \text { DQR } & \text { data quality report } \\ \text { FTIR } & \text { Fourier Transform Infrared } \\ \text { IR } & \text { infrared } \\ \text { LBLRTM } & \text { (line-by-line radiative transfer model) } \\ \text { LIDAR } & \text { light detection and ranging } \\ \text { MADS } & \text { Multiple AERI Data System } \\ \text { NSA } & \text { North Slope of Alaska } \\ \text { PBL } & \text { planetary boundary layer } \\ \text { QME } & \text { Quality Measurement Experiment } \\ \text { RASS } & \text { radio acoustic sounding system } \\ \text { RTE } & \text { radiative transfer equation } \\ \text { SGP } & \text { Southern Great Plains } \\ \text { SHEBA } & \text { Surface Heat Budget of the Arctic Ocean } \\ \text { SSEC } & \text { Space Science and Engineering Center } \\ \text { TWP } & \text { Tropical Western Pacific } \\ \text { UTC } & \text { Universal Time Coordinates } \\ \text { VAP } & \text { value-added product }\end{array}$

Also see the ARM Acronyms and Abbreviations.

\subsection{Citable References}

\section{References 2 and 3 provide outstanding detail on the AERI.}

1) Revercomb, H.E., H. Buijs, H.B. Howell, D.D. LaPorte, W.L. Smith, and L.A. Sromovsky. 2004. "Radiometric Calibration of IR Fourier Transform Spectrometers: Solution to a Problem with the HighResolution Interferometer Sounder." Applied Optics 27(15):3210-3218.

2) Knuteson, R.O., H.E. Revercomb, F.A. Best, N.C. Ciganovich, R.G. Dedecker, T.P. Dirkx, S.C. Ellington, W.F. Feltz, R.K. Garcia, H.B. Howell, W.L. Smith, J.F. Short, and D.C. Tobin. 2004. “Atmospheric Emitted Radiance Interferometer. Part I: Instrument Design.” Journal of Atmospheric and Oceanic Technology 21:1763-1776.

3) Knuteson, R.O. , H.E. Revercomb, F.A. Best, N.C. Ciganovich, R.G. Dedecker, T.P. Dirkx, S.C. Ellington, W.F. Feltz, R.K. Garcia, H.B. Howell, W.L. Smith, J.F. Short, and D.C. Tobin. 2004. “Atmospheric Emitted Radiance Interferometer. Part II: Instrument Performance.” Journal of Atmospheric and Oceanic Technology 21:1777-1789.

4) Brown, P.D. , S.A. Clough, N.E. Miller, T.R. Shippert, D.R. Turner, R.O. Knuteson, H.E. Revercomb, and W.L. Smith. 1995. "Initial Analyses of Surface Spectral Radiance Between Observations and Lineby-Line Calculations." Proceedings of the Fifth Atmospheric Radiation Measurement (ARM) Science Team Meeting." March 19-23, pp. 29-32. 


\section{Atmospheric Profiling}

Feltz, W.F., H.B. Howell, R.O. Knuteson, H.M. Woolf, and H E. Revercomb. 2003. "Near Continuous Profiling of Temperature, Moisture, and Atmospheric Stability Using the Atmospheric Emitted Radiance Interferometer (AERI).” Journal of Applied Meteorology 42:584-597.

Feltz, W.F., and J.R. Mecikalski. 2002. "Monitoring High Temporal Resolution Convective Stability Indices Using the Ground-Based Atmospheric Emitted Radiance Interferometer (AERI) During the 3 May 1999 Oklahoma/Kansas Tornado Outbreak.” Weather Forecasting 17:445-455.

Feltz, W.F., W.L. Smith, R.O. Knuteson, H.E. Revercomb, H.M. Woolf, and H.B. Howell. 1998. "Meteorological Applications of Temperature and Water Vapor Retrievals from the Ground-Based Atmospheric Emitted Radiance Interferometer (AERI).” Journal of Applied Meteorology 37:857-875.

He, Hui, W.W. McMillan, R.O. Knuteson, and W.F. Feltz. 2001. “Tropospheric Carbon Monoxide Column Density Retrieval During the Pre-Launch MOPITT Validation Exercise.” Atmospheric Environment 35:509-514.

Smith, W.L, W.F. Feltz, R.O. Knuteson, H.E. Revercomb, H.B. Howell, and H.M. Woolf. 1999. “The Retrieval of Planetary Boundary Layer Structure Using Ground-Based Infrared Spectral Radiance Measurements.” Journal of Atmospheric and Oceanic Technology 16:323-333.

Smith, W.L., H.E. Revercomb, H.B. Howell, H.M. Woolf, R.O. Knuteson, R.G. Dedecker, M.J. Lynch, E.R. Westwater, R.G. Strauch, K.P. Morton, B. Stankov, M.J. Falls, J. Jordan, M. Jacobsen, W.F. Daberdt, R. McBeth, G. Albright, C. Paneitz, G. Wright, P.T. May, and M.T. Decker. 1990. “GAPEX: A Ground-Based Atmospheric Profiling Experiment.” Bulletin of the American Meteorological Society 71(3).

Turner, D.D., W.F. Feltz, and R.A. Ferrare. 2000. "Continuous Water Profiles from Operational GroundBased Active and Passive Remote Sensors.” Bulletin of the American Meteorological Society 81:13011317.

\section{Cloud Retrieval}

Collard, A.D., S.A. Ackerman, W.L. Smith, X. Ma, H.E. Revercomb, R.O. Knuteson, and S.-C. Lee. 1995. "Cirrus Cloud Properties Derived from High Spectral Resolution Infrared Spectrometry during FIRE II. Part III: Ground-Based HIS Results.” Journal of the Atmospheric Sciences 52:4264-4275.

DeSlover, D.H., W.L. Smith, P.K. Piironen, and E.W. Eloranta. “A Methodology for Measuring Cirrus Cloud Visible-to-Infrared Spectral Optical Depth Ratios.” Journal of Atmospheric and Oceanic Technology 16:251-262.

Turner, D.D. submitted. “Arctic Mixed-Phase Cloud Properties from AERI Observations, Part I: Theory and Simulations." Journal of Applied Meteorology. 
Turner, D.D. submitted. "Arctic mixed-phase cloud properties from AERI observations, Part II: Results from SHEBA.” Journal of Applied Meteorology.

Turner, D.D., S.A. Ackerman, B.A. Baum, H.E. Revercomb, and P. Yang. 2003. "Cloud Phase Determination Using Ground-Based AERI Observations at SHEBA.” Journal of Applied Meteorology 42:701-715.

\section{IR Modeling}

Tobin, D.C., and coauthors. "Downwelling Spectral Radiance Observations at the SHEBA Ice Station: Water Vapor Continuum Measurements from 17 to 26 um.” Journal of Geophysical Research 104:20812092.

D.D. Turner, D.C. Tobin, S.A. Clough, P.D. Brown, R.G. Ellingson, M.J. Mlawer, R.O. Knuteson, H.E. Revercomb, T.R. Shippert, and W.L. Smith. submitted. "The QME AERI LBLRTM: A Closure Experiment for Downwelling High Spectral Resolution Infrared Radiance.” Journal of Atmospheric Science.

\section{Instrument}

Minnett, P.J., R.O. Knuteson, F.A. Best, B.J. Osborne, J.A. Hanafin, and O.B. Brown. 2001. "The Marine-Atmospheric Emitted Radiance Interferometer: A High-Accuracy, Seagoing Infrared Spectroradiometer.” Journal of Atmospheric and Oceanic Technology 18:994-1013.

\section{Oceanic / Land Surface Remote Sensing}

Kearns, E.J., J.A. Hanafin, R.H. Evans, P.J. Minnett, and O.B. Brown. 2000. “An Independent Assessment of Pathfinder AVHRR Sea Surface Temperature Accuracy Using the Marine Atmosphere Emitted Radiance Interferometer (MAERI).” Bulletin of the American Meteorological Society 81:15251536.

McKeown, W., F. Bretherton, H.L. Huang, W.L. Smith, and H.E. Revercomb. 1995. "Sounding the Skin of Water: Sensing Air-Water-Interface Temperature-Gradients with Interferometry.” Journal of Atmospheric and Oceanic Technology 12:1313-1327.

Smith, W.L., R.O. Knuteson, H.E. Revercomb, W. Feltz, H.B. Howell, W.P. Menzel, N. Nalli, O. Brown, J. Brown, P. Minnett, and W. McKeown. 1996. "Observations of the Infrared Radiative Properties of the Ocean - Implications for the Measurement of Sea Surface Temperature via Satellite Remote Sensing.” Bulletin of the American Meteorological Society. 